Universite de LAUSANNE - FACUlTE dE BIOlogie ET DE MEDECINE

DEPARTEMENT DE MEDECINE

DIVISION DE PHYSIOPATHOLOGIE CLINIQUE

Chef de division : Professeur Bernard WAEBER

\title{
PROFOUND IMPACT OF UNCOMPLICATED PREGNANCY on Diastolic, but not Systolic PUlse Contour OF AORTIC PRESSURE
}

\section{THESE}

Présentée à la Faculté de biologie et de médecine de l'Université de Lausanne pour l'obtention du grade de

DOCTEUR EN MEDECINE

\section{NG \\ 410 \\ D)el}

\author{
par \\ Anne KIEL-DELACHAUX \\ Médecin diplômée de la Confédération Suisse \\ $3 \mu T+3440$ \\ Originaire de Lausanne (Vaud)
}




\section{RESUME}

\section{L'objectif de cette étude était de déterminer l'impact de la grossesse non compliquée sur l'onde de pouls de la pression aortique centrale.}

\section{Méthode :}

66 femmes au total avec une grossesse simple ont été réparties en trois groupes selon le stade de leur gestation : premier trimestre $(T 1, n=22)$, deuxième trimestre $(T 2, n=20)$ et troisième trimestre $(T 3, n=24)$. Le groupe contrôle $(C, n=21)$ était constitué de femmes non enceintes, en bonne santé habituelle, prenant une contraception oestroprogestative.

La tonométrie d'aplanation a été utilisée pour l'acquisition des ondes de pouls centrale: un appareil disponible dans le commerce (SphygmoCor) permet l'enregistrement de l'onde de pouls périphérique avec un tonomètre d'aplanation de l'artère radiale au niveau du poignet, puis effectue sa transformation en sa forme centrale, grâce à une analyse de Fourrier et une fonction de transfert.

L'influence des ondes réfléchies sur l'onde de pouls a été déterminée non seulement pendant la systole (augmentation systolique), comme on procède habituellement dans l'analyse de l'onde de pouls, mais aussi pendant la diastole (augmentation diastolique).

\section{Résultats :}

Au cours de la grossesse, les pressions centrales systolique et diastolique sont restées inchangées et comparables aux valeurs mesurées chez les femmes qui ne sont pas enceintes. Dans le groupe contrôle, l'augmentation systolique s'élevait à $8.1 \pm 7.5 \%$ de la pression de pouls; il n'y avait pas de différence statistiquement significative avec les valeurs obtenues chez les femmes enceintes, et ce, à n'importe quel stade de la grossesse

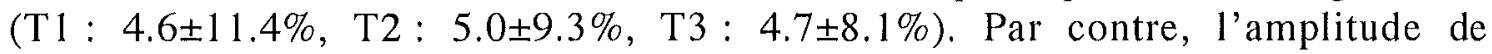
l'augmentation diastolique diminuait avec la progression de la grossesse (C $6.5 \pm 2.4 \%$, T1 : $5.2 \pm 3.1 \%$, T2 : $3.8 \pm 2.6 \% ; P=0.002$ versus $C ; \mathrm{T} 3: 2.3 \pm 2.0 \% ; P<0.0001$ versus $\mathrm{C}$ et $P=0.004$ versus T1).

\section{Conclusion :}

La grossesse ne modifie pas la forme de l'onde de pouls systolique centrale, ce qui implique de la part du système cardiovasculaire une adaptation fine à la demande croissante de flux sanguin, et ce, à tous les stades de la grossesse. Par contre, l'amplitude de l'onde de réflexion atteignant l'aorte pendant la diastole diminue progressivement au cours de la grossesse.

\section{Perspectives :}

De récentes études montrent qu'une valeur anormalement haute de l'augmentation systolique de la pression centrale, comme on peut la déterminer avec la tonométrie d'aplanation, pourrait être un indice de trouble hypertensif de la grossesse débutant. Cette technique simple pourrait être d'autant plus facile à mettre en œuvre si les valeurs normales pour l'augmentation systolique étaient indépendantes du stade de la grossesse, comme le suggèrent nos résultats, du moins pour les mesures prises en position assise. 


\section{REMERCIEMENTS}

Je tiens à remercier toutes les personnes ayant contribué de près ou de loin à la réalisation de ce travail, qui m'ont soutenu et qui m'ont fait partager leurs connaissances. Je remercie en particulier :

Le Professeur François Feihl, qui a permis l'aboutissement de ce travail grâce à ses connaissances pratiques et théoriques et à son investissement personnel. J'ai énormément appris à son contact.

Le Professeur Bernard Waeber, directeur de cette recherche et qui en est également à l'origine, pour son enthousiasme et son soutien.

L'équipe de la division de physiopathologie clinique du CHUV, ainsi que Madame Françoise Bilat.

Le personnel de la policlinique de gynécologie-obstétrique du CHUV pour son accueil et sa collaboration. 
Je dédie ce travail à Ralf Kiel qui m'a soutenue et encouragée tout au long de la réalisation de cette étude. 


\title{
Profound impact of uncomplicated pregnancy on diastolic, but not systolic pulse contour of aortic pressure
}

\author{
Anne Delachaux ${ }^{a}$, Bernard Waeber ${ }^{a}$, Lucas Liaudet ${ }^{b}$, Patrick Hohlfeld ${ }^{c}$ and \\ François Feihl ${ }^{\mathrm{a}}$
}

\begin{abstract}
Objective To evaluate the impact of uncomplicated pregnancy on the pulse contour of central aortic pressure.
\end{abstract}

\begin{abstract}
Methods A total of 66 women with singleton pregnancy were grouped according to pregnancy duration: first trimester (T1, $n=22$ ), second trimester (T2, $n=20$ ), and third trimester (T3, $n=24)$. Non-pregnant healthy women, who took combined oral contraception, were included as controls $(C, n=21)$. The pulse contour of aortic pressure was obtained with radial applanation tonometry, using a commercial device (SphygmoCor). The influence of reflected waves on the contour was evaluated not only in systole, as usual with pulse contour analysis (systolic augmentation), but also in diastole (diastolic augmentation).
\end{abstract}

Results Throughout pregnancy, central systolic and diastolic blood pressure remained unchanged and comparable to values in the non-pregnant state. Systolic augmentation amounted to $8.1 \pm 7.5 \%$ of pulse pressure in the control group (mean \pm SD), and there was no statistically significant deviation from this value at any stage of pregnancy $(\mathrm{T} 1,4.6 \pm 11.4 \% ; \mathrm{T} 2,5.0 \pm 9.3 \%$; $\mathrm{T} 3$, $4.7 \pm 8.1 \%)$. In contrast, the amplitude of the diastolic augmentation wave progressively declined with advancing pregnancy (C, $6.5 \pm 2.4 \% ; \mathrm{T} 1,5.2 \pm 3.1 \% ; \mathrm{T} 2,3.8 \pm 2.6 \%$; $P=0.002$ versus $C, T 3,2.3 \pm 2.0 \% ; P<0.0001$ versus $C$ and $P=0.0004$ versus $\mathrm{T} 1$ )

Conclusion The systolic shape of the central aortic pressure contour is left unaltered by pregnancy, implying a finely tuned adaptation of the cardiovascular system to the increased demand for blood flow at all stages of the gravid state. In contrast, the amplitude of reflection waves reaching the aortic root in diastole progressively decreases with advancing pregnancy. J Hypertens 24:1641-1648 (C) 2006 Lippincott Williams \& Wilkins.

Journal of Hypertension 2006, 24:1641-1648

Keywords: aorta, blood pressure, diastole, haemodynamic phenomena, pregnancy, systole

aDivision de Physiopathologie Clinique, Département de Médecine, ${ }^{\mathrm{b}}$ Service des Soins Intensifs and ${ }^{\mathrm{C} D}$ Département de Gynécologie-Obstétrique-Génétique, Centre Hospitalier Universitaire Vaudois (CHUV), Lausanne, Switzerland

Correspondence and requests for reprints to François Feihl, MD, PPA, BH10-701, CHUV, 1011 Lausanne, Switzerland

Tel: +412131414 23; fax: +41213141432; e-mail: francois,feihl@chuv,ch

Sponsorship: This work was entirely supported by departmental funds.

Received 14 November 2005 Accepted 27 March 2006

essentially the aorta $[2,3,5,6]$. Such a change acts to limit the amplitude of the forward pressure wave generated in this vessel by left ventricular ejection. In addition, it diminishes the propagation velocity along the arterial tree of both the forward and the reflected pressure waves. The latter, which travels back from the peripheral sites of reflection towards the heart, will then tend to reach the ascending aorta relatively late in systole, or even in diastole. In such conditions, one would expect little or no augmentation of proximal aortic pressure by the reflected wave.

There are only limited human data concerning the actual impact of normal pregnancy on the central aortic pressure waveform. For obvious reasons, invasive measurements are not ethically acceptable in this setting. One study provided serial non-invasive recordings of pulse pressure in the subclavian artery of healthy women in the first, second and third trimester of pregnancy, together with Doppler ultrasound measurements of blood flow velocity in the ascending aorta. Inference was made that 
pregnancy indeed delayed the occurrence of reflected waves, but systolic augmentation of aortic pressure perse was not reported [2].

Applanation tonometry is an easily applicable non-invasive method for the assessment of the pressure waveform in the ascending aorta [10]. The peripheral pulse is recorded by means of a piezoelectric high-fidelity pressure sensor applied on the skin overlaying a peripheral, superficial artery. The acquired peripheral pulse waveform is then mathematically transformed into its central version, using Fourier analysis and a generalized transfer function (GTF) [11]. The best site to record the peripheral pulse wave is at the wrist, where the radial artery is easily accessible in the majority of individuals. The radial artery recording is calibrated with blood pressure measured at the level of the brachial artery, because blood pressure is practically identical in both vessels. The mathematical derivation to transform peripheral recordings into the central pressure waveform has been validated against invasive measurements $[12,13]$, and has reasonable reproducibility $[14,15]$. With this method, it has been shown that pre-eclampsia in the third trimester of pregnancy is associated with an abnormally high augmentation of the central systolic pressure by reflected waves [16]. To our knowledge, applanation tonometry of the radial artery has been used only once to characterize the effects of a normal pregnancy on the central arterial pressure waveform $[17,18]$. In that report, analysis was limited to systolic events.

In the present study, we examined the impact of uncomplicated pregnancy on the shape of the ascending aortic pressure pulse, as reconstructed with radial applanation tonometry. Equal attention was paid to the systolic and diastolic parts of the reconstructed waveforms.

\section{Methods}

\section{Subjects}

Sixty-six women with singleton pregnancy were recruited from the outpatient obstetrics clinic in our hospital and grouped according to pregnancy duration. The first trimester group (T1) included women with gestational age from the beginning of pregnancy until 13 weeks, the second trimester group (T2) from 14 until 26 weeks, and the third trimester group (T3) from 27 weeks until delivery. Demographic data are shown in Table 1. All subjects were in good health, except one who had multiple sclerosis, in the remission phase and without sequellae at the time of study. In particular, none of the study participants had any history of cardiovascular disease. Women with known or suspected complications during pregnancy, such as pregnancy-induced hypertension, gestational diabetes or pre-eclampsia, were excluded. Isolated proteinuria was also an exclusion criterion. There was no intake of any antihypertensive or cardiovascular drug. Medication at the time of the study was: antiemetica (six women in the first trimester), magnesium (one woman in the second trimester and eight women in the third trimester), vitamins and folic acid ( 15 women of all trimesters), antacid (aluminii oxidii hydricum: three women), paracetamol (four women) and mefenamic acid (one woman).

In addition, 21 non-pregnant women, who had been taking combined oral contraceptives for at least 2 months, were included in a control group (C). They were healthy, without any cardiovascular or gynaecological disease and did not take any other medication. The examination was performed outside the period of interruption of contraceptive medication.

All women were fully informed on the study protocol and gave their written consent. The investigation conformed with the principles outlined in the declaration of Helsinki, and was approved by the Institutional Review Board of our hospital.

\section{Experimental design}

As required in a cross-sectional study, each woman, whether pregnant or not, was examined only once.

Table 1 Characteristic of the subjects

\begin{tabular}{|c|c|c|c|c|}
\hline & \multirow{2}{*}{$\frac{\text { Non-pregnant }}{\text { Controls }}$} & \multicolumn{3}{|c|}{ Pregnant } \\
\hline & & 1st Trimester (T1) & 2nd Trimester (T2) & 3rd Trimester (T3) \\
\hline No. of subjects & 21 & 22 & 20 & 24 \\
\hline Duration of pregancy (weeks) & - & $10.4 \pm 1.9$ & $19.4 \pm 4.1$ & $34.6 \pm 3.7$ \\
\hline Age (years) & $27.0 \pm 4.1$ & $27.0 \pm 4.7$ & $28.8 \pm 5.0$ & $28.6 \pm 4.2$ \\
\hline Height $(\mathrm{cm})$ & $167 \pm 7$ & $164 \pm 5$ & $164 \pm 6$ & $167 \pm 8$ \\
\hline Weight (kg) & $56.8+7.0$ & $62.3 \pm 12.0$ & $60.7 \pm 12.4$ & $63.7 \pm 12.4$ \\
\hline BMI $\left(\mathrm{kg} / \mathrm{m}^{2}\right)$ & $20.4 \pm 2.3$ & $23.3 \pm 4.6$ & $22.8 \pm 3.6$ & $22.7 \pm 3.7$ \\
\hline \multicolumn{5}{|l|}{ Ethnic group } \\
\hline Caucasian & 20 & 13 & 18 & 18 \\
\hline Black & 0 & 2 & 0 & 2 \\
\hline Asian & 1 & 1 & 0 & 1 \\
\hline Others & 0 & 6 & 2 & 1 \\
\hline Smoker or ex-smoker & 8 & 7 & 9 & 7 \\
\hline
\end{tabular}

BMI, Body mass index (in pregnant women, refers to value just before pregnancy). Data are means $\pm S D$. No significant differences between groups. 
After 15 min of resting in the seated position, the right brachial blood pressure was assessed once using a mercury sphygmomanometer (Mercuro 300; Riester, Germany), and then the pulse wave was recorded three times on the right radial artery. Finally, three new measurements of blood pressure were made and averaged for calibration of the radial pulse. Individual parameter values derived from the pulse wave analysis were means obtained from the three aforementioned tonometric recordings.

All measurements were taken by the first author, in her fourth year of specialty training (general medicine), with subjects in the seated position and forearms supported by armrests.

\section{Pulse wave analysis}

The measurement of the radial pulse wave with applanation tonometry and the subsequent derivation of the aortic pulse wave were made using the SphygmoCor system (AtCor Medical, Sydney, Australia). In this method, a pen-shaped high-fidelity solid-state pressure transducer is used to flatten the radial artery at the wrist using gentle pressure. Data are collected directly into a portable computer using the SphygmoCor software, with an online display of waveforms in order to allow the best possible recording. Pulse waves acquired over a period of $10 \mathrm{~s}$ are converted to a central waveform, using the GTF, as described [11].

All pulse wave recordings made in the present study met the quality criteria defined by the manufacturer, namely a mean pulsatile amplitude of the raw tonometric signal higher than $80 \mathrm{mV}$, as well as a beat-to-beat variability of pulse pressure and of diastolic pressure less than $5 \%$ of average pulse pressure.

From the recorded waveforms, the SphygmoCor software calculates various indices, including the duration of the cardiac cycle, the duration of ventricular ejection, and the systolic augmentation index. Ejection duration is calculated from the radial pulse as the time from the foot of the pressure wave to the incisura. Systolic augmentation of aortic pressure caused by reflection (sometimes termed 'augmentation index') is defined as the pressure difference between the first and the second peaks of the aortic waveform, expressed as a percentage of the aortic pulse pressure.

\section{Further processing of the aortic pulse wave}

To estimate the mean aortic pressure profile of each group, the relevant individual waveforms were ensemble-averaged in each group of women using the following procedure, which took into account the variations of ejection duration and total length of cardiac cycle between subjects. Each individual waveform was broken down into a systolic and a diastolic part, as determined from the ejection duration provided by the SphygmoCor analysis software. The time abscissas of each part were linearly mapped to new time axes, in such a manner that, within a group of women, the durations of both systole and diastole became uniformly equal to the respective mean values for this group. The mapped waveforms were resampled at $128 \mathrm{~Hz}$ (i.e. the original sampling rate), using linear interpolation, and normalized relative to aortic pulse pressure. In this last step, which was taken to facilitate comparisons of waveform shapes between groups, diastolic pressure became $0 \%$ and peak systolic pressure became $100 \%$ of aortic pulse pressure.

Because a prominent diastolic wave was clearly visible on the raw inspection of many tracings, its amplitude was quantified on each individual dataset, as follows (see Fig. 2, inset). A straight line was drawn through the first data point in diastole, so as to have tangent contact with the later, upward concave part of the diastolic pressure decay. The amplitude of the superimposed diastolic wave was then read as the maximum positive vertical distance going from this line to the actual aortic pressure, within the time interval from the beginning of diastole to the time abscissa of the contact point. This amplitude was defined as the diastolic augmentation and expressed as a percentage of the aortic pulse pressure.

\section{Statistical analysis}

The mean values of each variable were compared between groups with simple analysis of variance. When the $F$ value was significant, pairwise comparisons were made using Fisher's least significant difference. The potential influence of heart rate, body height and weight on systolic augmentation and on the diastolic wave was tested with analysis of covariance (i.e. a linear model incorporating as independent predictors all aforementioned variables in addition to group membership). Computations related to statistical analysis were carried out using the JMP software (version 3.1; SAS Institute, Cary, North Carolina, USA). The alpha level of all tests was set at 0.05 . All data were summarized as the mean $\pm \mathrm{SD}$.

\section{Results}

As shown in Table 1, the four groups of subjects were well matched for age, body height, and smoking habits, three variables of potential impact on the shape of the arterial pulse [10]. Body weight tended to be lower in nonpregnant than in pregnant women, although this difference was not statistically significant.

Haemodynamic variables in the four groups of women are shown in Table 2. These data indicate that pregnancy had no influence on the systolic and diastolic values of either brachial or aortic pressure. Whether compared with non-pregnant conditions or early pregnancy (first and second trimester), late pregnancy (third trimester) was characterized by a $12 \%$ increase in heart rate $(P<0.001)$, 
Table 2 Haemodynamic data and pulse contour analysis

\begin{tabular}{|c|c|c|c|c|}
\hline & \multirow{2}{*}{$\frac{\text { Non-pregnant }}{\text { Controls }}$} & \multicolumn{3}{|c|}{ Pregnant } \\
\hline & & 1st Trimester (T1) & 2nd Trimester (T2) & 3rd Trimester (T3) \\
\hline No, of subjects & 21 & 22 & 20 & 24 \\
\hline Heart rate (beats $/ \mathrm{min})$ & $76 \pm 11$ & $80 \pm 10$ & $79 \pm 8$ & $89 \pm 8^{* *}, \$, \#$ \\
\hline \multicolumn{5}{|l|}{ Peripheral blood pressure ${ }^{a}$} \\
\hline Systolic $(\mathrm{mmHg})$ & $105 \pm 7$ & $107 \pm 11$ & $105 \pm 9$ & $110 \pm 10$ \\
\hline Diastolic $(\mathrm{mmHg})$ & $68 \pm 7$ & $65 \pm 9$ & $63 \pm 7$ & $64 \pm 8$ \\
\hline \multicolumn{5}{|l|}{ Central blood pressure ${ }^{b}$} \\
\hline Systolic $(\mathrm{mmHg})$ & $92 \pm 6$ & $92 \pm 10$ & $91 \pm 9$ & $93 \pm 8$ \\
\hline Diastolic $(\mathrm{mmHg})$ & $69 \pm 7$ & $66 \pm 9$ & $65 \pm 7$ & $66 \pm 8$ \\
\hline \multicolumn{5}{|l|}{ Ejection duration ${ }^{b}$} \\
\hline In milliseconds & $288 \pm 25$ & $288 \pm 23$ & $298 \pm 17$ & $278 \pm 20^{\#}$ \\
\hline In $\%$ of cardiac cycle & $36.3 \pm 3.6$ & $38.2 \pm 4.0^{*}$ & $39.2 \pm 3.0^{*}$ & $41.6 \pm 3.2^{* *, 5, \#}$ \\
\hline Central $\mathrm{d} \rho / \mathrm{d} t \max (\mathrm{mmHg} / \mathrm{s})^{\mathrm{b}}$ & $642 \pm 176$ & $691 \pm 155$ & $703 \pm 206$ & $708 \pm 146$ \\
\hline \multicolumn{5}{|l|}{ Central systolic augmentation (\%) } \\
\hline Uncorrected ${ }^{b}$ & $8.1 \pm 7.5$ & $4.6 \pm 8.1$ & $5 \pm 9.3$ & $4.7 \pm 8.1$ \\
\hline Corrected $^{b, c}$ & $8.7 \pm 6.6$ & $7.0 \pm 11$ & $7.0 \pm 8.0$ & $11 \pm 7.6$ \\
\hline
\end{tabular}

$\mathrm{d} \rho / \mathrm{d} t$ max, Maximal slope of the ascending central pressure pulse. ${ }^{\mathrm{a}}$ Measured by sphygmomanometry, ${ }^{b} \mathrm{Calculated}$ by the SphymoCor software. ${ }^{\mathrm{C} V a l u e}$ of systolic augmentation adjusted to a fixed heart rate of 75 beats. Data are means $\pm S D$. $* P<0.05 i^{* *} P<0.01: T 1, T 2$ or T3 versus $C$. ${ }^{5} P<0.05, T 2$ or T3 versus $T 1$. ${ }^{\#} P<0.05 T 3$ versus T2.

with ejection duration correspondingly shortened when expressed in milliseconds $(P=0.03)$ but occupying a somewhat greater proportion of the total cardiac cycle $(P<0.001)$. The systolic aortic augmentation index ranged from -15 to $+31 \%$ of pulse pressure. Being negative or zero in a quarter of subjects, it was of high apparent variability within groups (coefficient of variation close to or above $100 \%$ ), and did not significantly differ between groups $(P=0.55)$. This index could not be calculated in one subject because of the lack of a clearly defined inflection point on the ascending limb of the aortic pressure waveform, and was disregarded in two others because the calculated values were tagged as unreliable by the SphygmoCor software.

Systolic augmentation is clearly visible on the averaged aortic pressure waveforms in the shape of a peak occurring in the second half of the ejection period, separated from the first half by an inflection point (Fig. 1). In keeping with the aforementioned calculations, this feature appears unchanged by pregnancy. In contrast, the first half of diastole contains an upward convexity (diastolic wave), which is most noticeable in non-pregnant women and progressively wanes with advancing pregnancy. Consistent with the visual impression conveyed by Fig. 1, the amplitude of the diastolic wave, calculated from each individual data set as shown on the inset to Fig. 2, was highest in control subjects $(6.5 \pm 2.4 \%$ of pulse pressure), with a monotonous decrease from the first $(5.2 \pm 3.1 \%)$, to the second $(3.8 \pm 2.6 \%, P=0.002$ versus controls) and third trimester of pregnancy $(2.3 \pm 2.0 \%, P<0.0001$ versus controls, $P=0.0004$ versus first trimester).

It is known that systolic augmentation decreases with increasing heart rate [19], although the effect of this variable on the diastolic wave is unknown. Because of the slight heart rate acceleration noted in the third trimester of pregnancy (Table 2), two attempts were made to control for the influence of this variable. First, we tabulated the value of systolic augmentation corrected for heart rate, an adjustment offered by the SphygmoCor software (i.e. the AI@75 parameter listed in the program's output). As shown in the last line of Table 2, the conclusion of an essentially unaltered systolic augmentation

Fig. 1

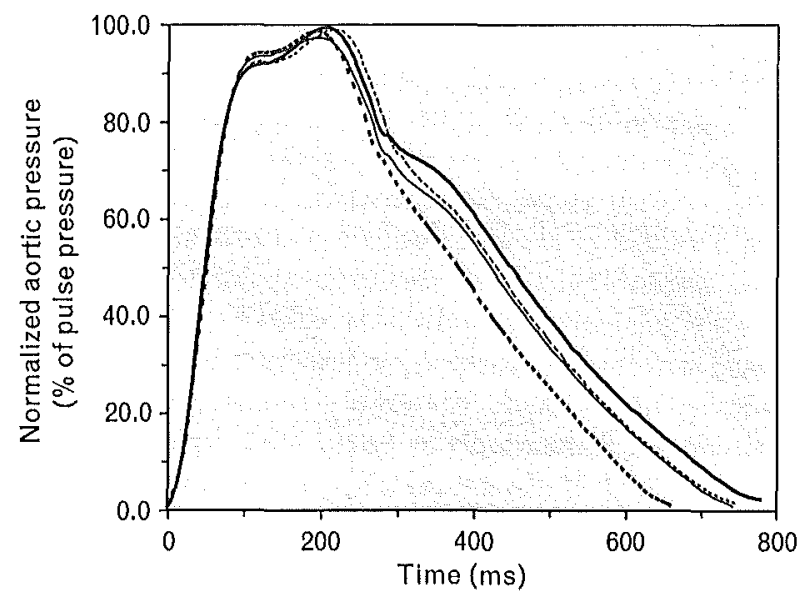

Average aortic pressure waveforms in the four groups of women. Aortic pressure waveforms were ensemble-averaged in each group using the following procedure, which took into account the variations in ejection duration and total length of cardiac cycle between subjects. Each individual waveform was broken down into a systolic and a diastolic part, as determined by the pulse wave analysis software provided with the SphygmoCor device. The time axes of each part were linearly mapped to new time axes, in such a manner that, within a group, the durations of systole and diastole became uniformly equal to the respective mean values for this group. The mapped waveforms were re sampled at $128 \mathrm{~Hz}$, using linear interpolation, and normalized relative to aortic pulse pressure. In this last step, which was taken to facilitate comparisons between groups, diastolic pressure became $0 \%$ and peak systolic pressure became $100 \%$ or aortic pulse pressure. Controls $(n=21) ;-$ pregnant 1st trimester $(n=22) ; \ldots \ldots$ pregnant 2nd trimester $(n=20) ; \ldots \ldots$ pregnant 3rd trimester $(n=24)$. 


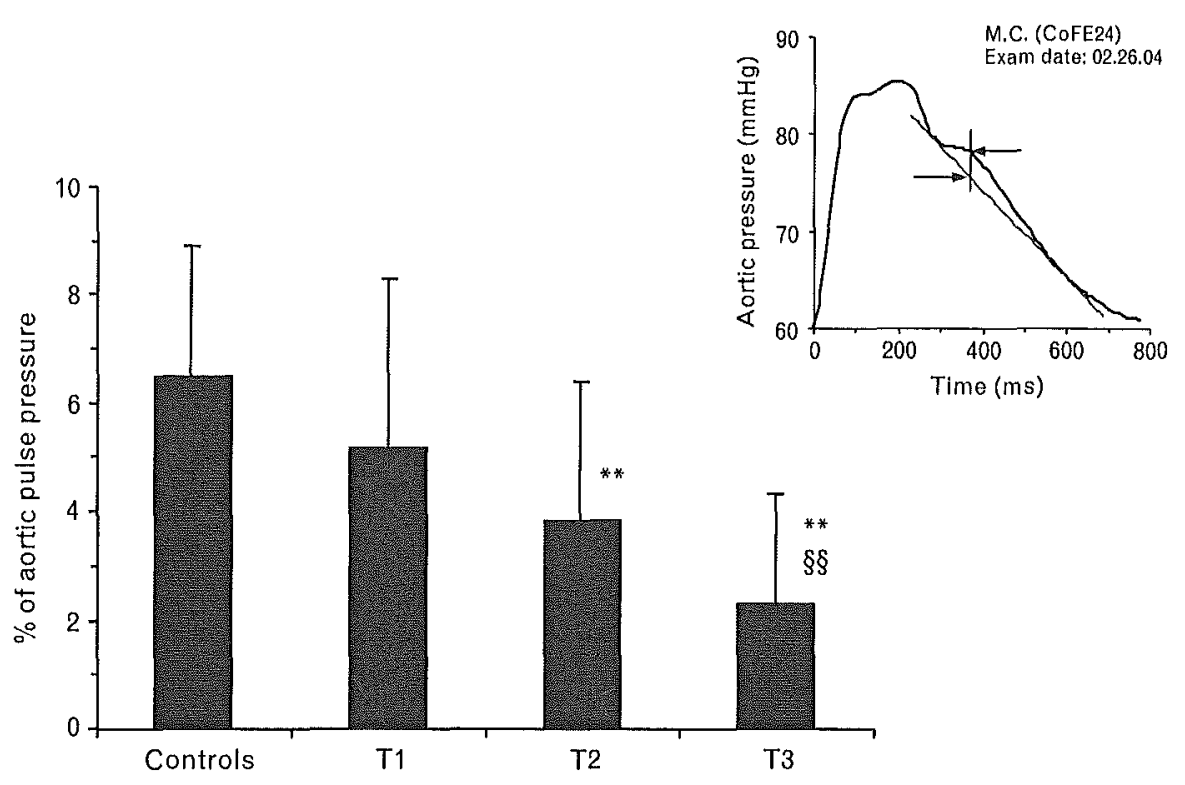

Amplitude of diastolic wave superimposed on the diastolic decay of aortic pressure. This amplitude was quantified on each individual dataset, as shown in the inset. A straight line was drawn through the first data point in diastole, so as to have tangent contact with the later, upward concave part of the diastolic pressure decay. Amplitude of the superimposed diastolic wave was then read as the maximum positive vertical distance going from this line to the actual aortic pressure, within the time interval from the beginning of diastole to the time abscissa of the contact point. T1, T2, and T3, respectively, designate the first, second, and third trimester of pregnancy. Data are means $\pm S D$. $* * P<0.01: T 1, T 2$ or T3 versus controls.

SSP $<0.01, T 2$ or $T 3$ versus T1.

throughout pregnancy was not modified. Second, we introduced heart rate as a covariate in the comparisons between study groups, using a model that included a heart rate by group interaction term. When adjusted in this fashion rather than by the SphygmoCor software, systolic augmentation remained unaffected by pregnancy $(P=0.52)$ and decreased by $3.4 \%$ of pulse pressure for each 10 beat $/ \mathrm{min}$ increase in heart rate $(P=0.0003)$. The interaction term was clearly non-significant $(P=0.84)$, indicating that this dependence of systolic augmentation on heart rate was the same irrespective of pregnancy status. In contrast, the amplitude of the diastolic wave remained strongly associated with the stage of pregnancy $(P=0.0001)$, but showed no relationship whatsoever with heart rate $(P=0.92)$. Further adjustments for age, body height and body weight had negligible influence on any of the above results. Interestingly, these last analyses disclosed an independent influence of age on the systolic and diastolic augmentations, without any interaction with pregnancy status $(P=0.31)$. For each additional age year, systolic augmentation increased by $0.6 \% \quad(P=0.003)$, whereas diastolic augmentation decreased by $0.2 \%$ $(P=0.001)$.

\section{Discussion}

In the present study, we characterized the impact of pregnancy on central aortic pressure, with particular consideration given to the shape of the central arterial pressure waveform. We anticipated a progressive modification of this waveform with advancing pregnancy, because of the profound effects of the gravid state on the dynamics of ventricular ejection as well as on the mechanics of conduit arteries and on peripheral resistance, all of which co-determine the shape of the central pressure pulse. The new findings are twofold. First, the systolic part of the central pressure waveform remains unaltered throughout pregnancy, Second, the pattern of diastolic decay undergoes a progressive modification, most marked in the third trimester.

An invasive measurement of aortic pressure was ethically not feasible in these healthy women. To achieve our goal, we therefore resorted to an indirect, non-invasive technique, which consisted of recording the radial pulse with applanation tonometry, and then using it to reconstruct aortic pressure mathematically using a GTF, the term 'generalized' referring to an assumption of constancy across subjects and conditions [10]. A clear limitation to the present study is the fact that the GTF has never been validated in pregnancy, as was done by direct invasive measurements in non-pregnant subjects $[11,13,20]$. Supporting the validity of aortic pressure waveform reconstruction in the pregnant women, the dependence of systolic augmentation on heart rate was similar in all four study groups (i.e. an average decrease by $3.4 \%$ of pulse pressure for each 10 beats/min increase in beating frequency) and 
remarkably close to the value of $3.9 \%$ observed in a study of non-pregnant subjects in whom controlled changes of heart rate were induced by pacing [19].

The central aortic pulse results from the additive superposition of a forward traveling pressure wave generated by ventricular contraction and of a reflection wave that travels backwards from the peripheral sites of reflection towards the heart [21]. The particular contour of central pulse pressure depends on the particular shape of either wave, as well as on the timing of one with respect to the other. 'The shape of the forward wave is related to the dynamics of ventricular ejection and to the mechanical properties of conducting arteries, notably their stiffness [22]. In addition to these factors, the shape of the backward wave depends on the spatial dispersion of the reflection sites, which current understanding predominantly locates in resistance arterioles $[23,24]$, although some reflection also takes place in larger vessels, as a result of impedance non-uniformities introduced by branching or by longitudinal changes in elastic wall properties (elastic tapering). Finally, the time delay between the reflected and the forward wave depends on the velocity of pressure pulse propagation (pulse wave velocity), which in turn is a decreasing function of arterial stiffness [25]. These considerations explain the agedependent changes in the aortic pulse morphology of healthy humans [26]. At one extreme, children have very compliant arteries and thus a low pulse wave velocity, such that aortic pressure augmentation caused by reflections essentially occurs in diastole. In the elderly by contrast, arteries are stiffer, pulse wave velocity is higher, and reflected waves reach the aorta predominantly in the second half of ventricular ejection, thus augmenting systolic central pressure. The pattern of central aortic pressure observed in the non-pregnant women who took part in the present study is an intermediate one, compatible with augmentation straddling end-systole and the first half of diastole (Fig. 1). This pattern is consistent with observations made by others in healthy young adults, using either non-invasive means similar to those employed in the present study [26] or invasive high-fidelity recordings of pressure in the ascending aorta [27]. Based on the above discussion, not only should systolic augmentation increase, but diastolic augmentation should also decrease with advancing age, as was indeed revealed by the statistical analysis of our data (see end of Results section). This latter observation comes in further support to the applicability of the G'TF in normal pregnancy.

Pregnancy potentially affects all determinants of the contour of aortic pressure pulse. Because of the accompanying increase in stroke volume, and thus flow in the course of ejection, the forward wave might alter its shape, but such a change seems minimized by the associated decrease in aortic characteristic impedance, which reflects a lower stiffness of the great vessels [2]. Consistent with the relative stability of the forward wave shape in the course of pregnancy, the maximal $\mathrm{d} p / \mathrm{d} t$ calculated from the upstroke of reconstructed aortic pressure was similar in the four groups of women included in the present study (Table 2). With respect to the non-pregnant state, the general peripheral vasodilation associated with pregnancy $[1,3]$ should reduce the amplitude of the reflected waves, and the latter should also reach the aorta later because of the lower propagation velocity along the more compliant conduction vessels [2]. Accordingly, the contour of aortic pressure in pregnancy should be characterized by a reduction in amplitude and a shift from systole to diastole of the augmentation caused by reflected wave. Consistent with this expectation, Smith et al. [17] recently found that uncomplicated pregnancy was associated with a statistically significant decline of systolic augmentation (mean \pm SD unpregnant controls $21 \pm 9.0 \% n=10$, first trimester pregnancy $14 \pm 7.6 \% n=20$, second trimester $10 \pm 9.8 \% \quad n=20$ third trimester $10 \pm 8.8 \% n=20$ ), but limited their analysis to the systolic part of the central aortic pressure waveform. Here, we provide additional information by demonstrating a stepwise amplitude reduction of the diastolic wave with progressing pregnancy (Figs 1 and 2). In our study, systolic augmentation was relatively unaltered (Table 2 and Fig. 1), which, taken at face value, would seem to contradict the report by Smith et al. [17]. This discrepancy can be explained, at least partly, by noting the more marked difference in heart rate between pregnant and control women in that report (third trimester $93 \pm 8$ beats/min, non-pregnant $69 \pm$ 11 beats $/ \mathrm{min}, P<0.001$ ), when compared with ours (Table 2), taking into consideration the known decline of systolic augmentation with beating frequency [19], a relationship quite apparent in our data as already mentioned. In contrast, the impact of pregnancy on diastolic augmentation, shown for the first time in the present study, had no independent association with (and therefore was presumably not mediated by) changes in heart rate.

With only reconstructed central aortic pressure available, any explanation of the discordant behaviour of systolic and diastolic augmentation observed in the course of pregnancy must remain speculative. There is general agreement on the presence in humans and many other mammals of two distinct groups of reflection sites, one in the upper part of the body (i.e. head and upper extremities), and one in the lower part (abdomen and legs) $[22,28,29]$. As compared with reflected waves from the lower body, those from the upper body travel a shorter length and thus reach the aortic root sooner. Computer simulations with models of the arterial system that incorporate this concept have generated aortic pressure waveforms, which, under the proper set of realistic assumptions, mimic very closely those of non-pregnant women shown in Fig. 1 [30], suggesting that the systolic and diastolic augmentations observed in the present 
study might correspond to reflections generated from the upper and lower parts of the body, respectively. In this configuration, systolic augmentation might be conserved thoughout pregnancy in spite of reduced peripheral resistance in the upper limb, as a result of the appearance of new cephalad reflection sites, not an unreasonable possibility in view of data indicating that, contrary to other vessels, the carotid arteries stiffen [31,32], and contrary to other vascular bed blood flow in the major cerebral arteries slightly decreases [33] in the course of pregnancy. On the other hand, general vasodilation in the lower part of the body would contribute to attenuate diastolic augmentation.

The progressive time-course of diastolic wave attenuation (Fig. 2) is intriguing when considering that the global hemodynamic pattern of pregnancy, namely the augmentation of cardiac output and diminution of peripheral vascular resistance, is already well established in the first trimester, with relatively few further changes thereafter $[1,2,7]$. A possible, although highly speculative, explanation for these contrasting behaviours could be that the growing presence of the gravid uterus, in spite of its modest contribution to global peripheral conductance [34] might nevertheless progressively increase the spatial dispersion of reflection sites in the lower part of the body, resulting in a spread-out backward wave of diminished amplitude reaching the aortic root in diastole.

In summary, we found that pregnancy had no effect on the systolic and diastolic values of central aortic pressure. In addition, we characterized the impact of pregnancy on the shape of the central aortic pressure pulse in systole, and for the first time in diastole. We found an unaltered systolic shape, contrasting with a progressive modification of the diastolic waveform.

\section{Conclusion}

Our results indicate for the first time a differential impact of uncomplicated pregnancy on the diastolic and systolic shapes of the central aortic pulse. Considering that the time-course of aortic pressure in systole is an essential determinant of left-ventricular afterload, the marked invariance of the systolic shape and peak pressure implies a finely tuned adaptation of the cardiovascular system to the increased demand for blood flow at all stages of the gravid state. Recent data indicate that an abnormally high systolic augmentation of the central aortic pulse, as determined from applanation tonometry of the radial artery, might be an indicator of incipient hypertensive disorders in pregnancy $[16,18]$. The use of this simple technique would be greatly facilitated if the normal range for systolic augmentation was independent of pregnancy stage, as our results imply at least for measurements taken in the seated position.

\section{Acknowledgments}

The authors wish to thank the staff at the outpatient clinic of the Gynecology-Obstetrics-Genetics Department, whose help was invaluable for enrollment. They also wish to thank all study participants.

\section{References}

1 Duvekot JJ, Cheriex EC, Pieters FA, Menheere PP, Peeters LH. Early pregnancy changes in hemodynamics and volume homeostasis are consecutive adjustments triggered by a primary fall in systemic vascular tone. Am J Obstet Gynecol 1993; 169:1382-1392.

2 Poppas A, Shroff SG, Korcarz CE, Hibbard JU, Berger DS, Lindheimer MD, Lang RM. Serial assessment of the cardiovascular system in normal pregnancy. Role of arterial compliance and pulsatile arterial load. Circulation 1997; 95:2407-2415.

3 Spaanderman ME, Willekes C, Hoeks AP, Ekhart TH, Peeters LL. The effect of pregnancy on the compliance of large arteries and veins in healthy parous control subjects and women with a history of preeclampsia. Am J Obstet Gynecol 2000; 183:1278-1286.

4 MacGillivray I, Rose GA, Rowe B. Blood pressure survey in pregnancy. Clin Sci 1969; 37:395-407.

5 Edouard DA, Pannier BM, Lokkndon GM, Cuche JL, Safar ME. Venous and arterial behavior during normal pregnancy. Am J Physiol 1998; 274:H1605-H1612.

6 Hu J, Björklund A, Nyman M, Gennser G. Mechanical properties of large arteries in mother and fetus during normal and diabetic pregnancy. J Matern Fetal Invest 1998; 8:185-193.

7 Chapman AB, Abraham WT, Zamudio S, Coffin C, Merouani A, Young $D$, et al. Temporal relationships between hormonal and hemodynamic changes in early human pregnancy. Kidney int 1998; 54:2056-2063.

8 Moutquin JM, Rainville C, Giroux L, Raynauld P, Amyot G, Bilodeau R, Pelland N. A prospective study of blood pressure in pregnancy; prediction of preeclampsia. Am J Obstet Gynecol 1985; 151:191-196.

9 Thadhani R, Ecker JL, Kettyle E, Sandler L, Frigoletto FD. Pulse pressure and risk of preeclampsia; a prospective study. Obstet Gynecol 2001; 97:515-520.

10 O'Rourke MF, Pauca A, Jiang XJ. Pulse wave analysis, Br J Clin Pharmacol $2001 ; 51: 507-522$.

11 Chen $\mathrm{CH}$. Estimation of central aortic pressure waveform by mathematical transformation of radial tonometry pressure. Validation of generalized transfer function. Circulation 1997; 95:1827-1836,

12 O'Rourke MF, Pauca A, Kon N, Tong W, Yung W, Qaasem A, Avolio A. Calibrated ascending aortic pressure wave can be derived from the radial pulse using a generalized transfer function [Abstract]. Am J Hypertens 1999; 12 (Suppl. 1):166.

13 Gallagher D, Adji A, O'Rourke MF. Validation of the transfer function technique for generating central from peripheral upper limb pressure waveform. Am J Hypertens $2004 ; 17: 1059-1067$.

14 Filipovsky J, Svobodova V, Pecen L. Reproducibility of radial pulse wave analysis in healthy subjects. $J$ Hypertens $2000 ; 18: 1033-$ 1040.

15 Wilkinson IB. Reproducibility of pulse wave velocity and augmentation index measured by pulse wave analysis. Curr Hypertens Rep 1999; 1:204-211.

16 Elvan-Taspinar A, Franx A, Bots ML, Bruinse HW, Koomans HA, Central hemodynamics of hypertensive disorders in pregnancy. Am J Hypertens $2004 ; 17: 941-946$.

17 Smith SA, Morris JM, Gallery ED. Methods of assessment of the arterial pulse wave in normal human pregnancy. Am J Obstet Gynecol 2004; 190:472-476.

18 Ronnback $\mathrm{M}_{1}$ Lampinen $\mathrm{K}$, Groop $\mathrm{PH}$, Kaaja R. Pulse wave reflection in currently and previously preeclamptic women. Hypertens Pregnancy 2005; 24:171-180.

19 Wilkinson IB, MacCallum H, Flint L, Cockcroft JR, Newby DE, Webb DJ. The influence of heart rate on augmentation index and central arterial pressure in humans. J Physiol (Lond) 2000; 525:263-270.

20 Karamanoglu M, O'Rourke MF, Avolio AP, Kelly RP. An analysis of the relationship between central aortic and peripheral upper limb pressure waves in man. Eur Heart J 1993; 14:160-167.

21 Quick CM, Berger DS, Noordergraaf A. Constructive and destructive addition of forward and reflected arterial pulse waves. Am J Physio/ 2001; 280:H1519-H1527.

22 Nichols WW, O'Rourke MF. Chap, 11: Vascular impedance. In: McDonald's blood flow in arteries, London: Edward Arnold; 1990. pp. 283-329. 
23 Westerhof $N_{1}$ Sipkema $P$, van den Bos GC, Elzinga G. Forward and backward waves in the arterial system. Cardiovasc Res 1972; 6:648-656.

24 Nichols WW, O'Rourke MF. Chap. 9: Wave reflections. In: McDonald's blood flow in arteries. London: Edward Arnold; 1990. pp. 251-269.

25 Nichols WW, O'Rourke MF. Chap. 4: Properties of the arterial wall. In: McDonald's blood flow in arteries. London: Edward Arnold; 1990. pp. $77-124$.

26 Kelly R, Hayward C, Avolio A, O'Rourke M. Noninvasive determination of age-related changes in the human arterial pulse. Circulation 1989; 80:1652-1659.

27 Latham RD, Westerhof N, Sipkema P, Rubal BJ, Reuderink P, Murgo JP. Regional wave travel and reflections along the human aorta: a study with six simultaneous micromanometric pressures. Circulation 1985; 72:12571269.

28 Campbell KB, Burattini R, Bell DL, Kirkpatrick RD, Knowlen GG, Time-domain formulation of asymmetric $t$-tube model of arterial system. Am J Physiol 1990; 258:H1761-H1774.

29 Burattini R, Campbell KB. Comparative analysis of aortic impedance and wave reflection in ferrets and dogs, Am JPhysiol 2002; 282:H244-H255.

30 Karamanoglu $M_{1}$ Gallagher $D E_{1}$ Avolio AP, O'Rourke MF. Functional origin of reflected pressure waves in a multi branched model of the human arterial system. Am J Physiol 1994; 267:H1681-H1688.

31 Visontai Z, Lenard Z, Studinger P, Rigo J Jr, Kollai M. Impaired baroreflex function during pregnancy is associated with stiffening of the carotid artery. Ultrasound Obstet Gynecol 2002; 20:364-369.

32 Mersich B, Rigo J Jr, Besenyei C, Lenard Z, Studinger $P$, Kollai M. Opposite changes in carotid versus aortic stiffness during healthy human pregnancy. Clin Sci 2005; 109:103-107.

33 Zeeman GG, Hatab M, Twickler DM. Maternal cerebral blood flow changes in pregnancy. Am J Obstet Gyneco/ 2003; 189;968-972.

34 Duvekot JJ, Peeters UL. Maternal cardiovascular hemodynamic adaptation to pregnancy [Review]. Obstet Gynecol Surv 1994; 49 (12 Suppl.): $\mathrm{S1-S14.}$ 